\title{
INFLUENCIA DOS EXERCICIOS RESPIRATÓRIOS E DO ESTADO CIVIL NO COMPORTAMENTO DA PARTURIENTE
}

\author{
Wanda Escobar da Silva Freddi *
}

\begin{tabular}{|l|c|}
\cline { 2 - 2 } & $\mathrm{RBEn} / 01$ \\
\hline
\end{tabular}

FREDDI, W.E.S. - Influência dos exercícios respiratórios e do estado civil no comportamento da parturiente. Rev. Bras. EnP.; DF, $28: 7-19,1976$,

\section{INTRODUÇÃO}

Há uma vasta literatura pertinente aos diferentes métodos de preparo para o parto, incluindo a prática do exercício respiratório, objetivando a diminuição da dor ou a sua abolição.

Tanto o método de Read (28), como o método russo elaborado por Velvowsky e colaboradores e descrito por Nicolaiev (24), utilizam-se dos exercícios respiratórios, embora a maneira como são realizados e os efeitos que procuram alcançar sejam interpretados diferentemente.

Para READ (28), "respiração correta é a base da boa saúde". Baseado nisto, preconiza os exercícios respiratórios, durante a gravidez, para manterem a gestante em boas condições físicas e, concomitantemente facilitarem o crescimento fetal, garantindo condições vitais ao feto. Por outro lado, a respiração correta e a boa postura da gestante diminuem os prováveis desconfortos causados pela distensão uterina. Read recomenda a respiração profunda mais rápida (atingindo de 25 a 28 movimentos por minuto) no primeiro período do trabalho de parto, quando as contrações são mais intensas. No segundo periodo do trabalho de parto, aconselha, durante a contração, a apnéia voluntária e a respiração ofegante, com 0 ritmo de 35 a 40 movimentos por minuto.

Os exercícios respiratórios são valcrizados pelos seguidores de Read e ensinados de diferentes modos, não havendo muita explicação sobre o mecanismo de ação desses exercícios, que são indicados, geralmente, para facilitarem o relaxamento da gestante e da parturiente. Entre os discipulos de Read que adotaram os exercícios respiratórios, conforme sua técnica ou com pequenas modificaçōes, destacaram-se Heardman (16), Thoms (33), Hirsh (17), Cerruti (5), Blank (2) e Goodrich (14).

Os exercícios respiratórios utilizados no método psicoprofilático, segundo a técnica elaborada por Velvovsky e co-

* Professora Assistente Doutora das Disciplinas Enfermagem Obstétrica e Néo-Natal e Enfermagem Ginecológica da Escola de Enfermagem da USP.

* Trabalho premiado no XXVII C.B.Ene. 
FREDDI, W.E.S. - Influência dos exercícios respiratórios e do estado civil no comprrtamento da parturiente. Rev. Bras Enf.; DF, 28 : 7-19, 1976.

laboradores, e descrita por Nicolaiev (24), Chertok (7) e Gavensky (13), são indicados como um processo do parto, ativando o córtex e favorecendo a elevação do tônus cortical, impedindo o início de sensaçōes dolorosas. São respirações profundas, amplas e rítmicas executadas durante as contrações; a parturiente deve inspirar e expirar profundamente, mantendo um ritmo semelhante ao da respiração físiológica, isto é, de 16 a 18 movimentos por minuto. Nicolaiev (24) recomenda a apnéia voluntária para ser aplicada, durante as contraçōes, no período expulsivo, e a respiração freqüente e superficial, por sua vez, durante 0 desprendimento cefálico.

LAMAZE et al. (20 e 21) conservaram os mesmos princípios do método soviético, mas com alterações quanto à sua aplicação prática. Substituíram a respiração profunda e ampla, indicada para 0 período de dilatação, pela superficial e rápida. A respiração superficial deve ser utilizada pela parturiente quando esta apresentar $5 \mathrm{~cm}$ de dilatação. Antes, deve ser lenta e profunda. No período expulsivo, recomendam a apnéia voluntária durante a contração, e a respiração ofegante no desprendimento do pólo cefálico.

$O$ que se observa, no confronto entre os vários métodos de preparo para o parto, é que todos utilizam os exercícios respiratórios, embora, teoricamente, expliquem de maneira diferente 0 mecanismo da sua ação.

A maioria dos autores adeptos aos diversos métodos de preparação para o parto dão ênfase aos resultados obtidos na diminuição ou abolição da dor, na parturiente que adquirlu novos reflexos condicionados, úteis ao parto, e às suas reaçōes frente a esta nova situação. obvio que, abolindo ou atendendo a dor e a sua repercussão nociva sobre o organismo materno, outros benefícios advêm para a mãe e para o feto.
LAMAZE (19) obteve em 3.370 parturientes preparadas previamente para o parto, 20,7\% de comportamento "excelente" e $44,2 \%$ de "muito bom" e "bom".

BOCCI et al. (3), em 248 gestantes preparadas no "Centro de Torino", obtiveram: comportamento ótimo em $40,3 \%$; bom em $44,3 \%$; medíocre, em $10,8 \%$ e insucesso, em $4,8 \%$.

CERRUTI (5) preparou 80 gestantes, pelo método de Read, e 20 pelo método psicoprofilático, obtendo resultados equivalentes nos dois métodos; destas 100 parturientes, $42,0 \%$ foram classificadas com comportamento "ótimo" e $27 \%$ com "bom".

PIERFEDERICI (26) observou o comportamento de 538 primiparas preparadas pelo método psicoprofilático, classificou 50,9\% com comportamento "ótimo" e $29,18 \%$ como "bom".

NICOLAIEV, citado por Cerruti (6), obteve $85 \%$ de resultados favoráveis, concernentes à analgesia e ao comportamento das parturientes preparadas.

SBRIGLIO et al. (30), aplicando a técnica fisioterápica respiratória em 239 gestantes, classificaram, no trabalho de parto, $84,3 \%$ com comportamento "ótimo", $10,8 \%$ "medíocres" e $4,8 \%$ "insucesso". Nesta técnica, os exercícios respiratórios são acompanhados por um estímulo sonoro, agradável tanto no preparo da gestante, como durante o trabalho de parto.

Pode-se constatar, pelo exposto, que a preparação da gestante é de suma importância para o evolver do trabalho de parto. Há, porém, um grande número de gestantes que se privam deste benefício, ou por falta de conhecimento dos métodos existentes, ou porque residem em cidades ou zonas rurais que não contam com cursos de preparação para o parto. De um modo geral, os autores que preconlzam o emprego de tais métodos recomendam aos obstetras, às en- 
FREDDI, W.E.S. - Influência dos exercícios respiratórios e do estado civil no comp:rtamento da parturiente. Rev. Brs. Enf.; DF, 28 : 7-19, 1976.

fermeiras obstétricas e às obstetrizes que dispensem às parturientes os mesmos culdados e técnicas da preparação psicoprofilática.

SCKUWARCZ (31), na Argentina, relata que obteve, em 100 parturientes condicionadas durante o parto, $71 \%$ de resultados muito bom e bons (primiparas, $73,1 \%$ e multíparas, $68,7 \%$ ).

TONNELLIER e MOGGIA (34), na Argentina, apresentaram estudo estatístíco de 299 partos com preparação intraparto, sendo $84,73 \%$ normais. Em 272 parturientes, durante a primeira metade da dilatação, obtiveram $41,18 \%$ de comportamento excelente e, em 285 parturientes, na segunda metade da dilatação, $37,55 \%$. No periodo expulsivo, em 254 casos, houve $82,28 \%$ classificadas como "comportamento excelente".

GUASTALA (15), SHWARTZ (32), SALA (1963). DONATO (9), FERNANDEZ (11) e GAVENSKY (1971) são também defensores da assistência à parturiente não preparada, de acordo com os princípios do método de preparação para o parto.

Parece-nos importante ressaltar que o temor e a tensão emocional sentidos pela parturiente, principalmente primigesta, pode ser reforçado por diferentes causas. Podemos citar, como exemplo: o evolver patológico do parto; a preocupação da mulher, durante o trabalho de parto, com o destino, possivelmente desfavorável, de seu fillho (por exemplo, quando é llegitimo); a ansiedade causada pela sua própria situação difícil, etc. Poucos autores preocupam-se com a influência do estado civil no comportamento da parturiente.

DONEIC, et al. (10) comentam que as gestantes solteiras, geralmente têm medos terrificantes do parto. Alertam as enfermeiras que trabalham nos hospitais para que não se esqueçam das necessidades emocionais das parturientes solteiras provavelmente esquecidas por seus famillares e amigos, e vendo, na enfermeira um ponto de apoio.

LAMAZE et al. (20), interpretando as possíveis causas de fracassos do método do "Parto Sem Dor", destacam as causas psicológicas inerentes à mulher solteira, que vive sob a angústia da interrogação que envolve seu próprio futuro e o futuro de seu fillho.

VISENTINI et al. (35) consideraram, em seu trabalho, a influência de dois fatores, na assistência à parturiente solteira: um, é o medo das dores que terá de suportar sozinha, sem o apolo do marido e, muitas vezes, do médico; outro é a preocupação pela situação nova e difícll que terá que enfrentar, com o nascimento de seu filho. Além disso, a ausência ou a indiferença (quando não a hostilldade) dos familiares contribuem muito para a existêncla desse estado de desajustamento e de apreensão. Os autores prepararam para o parto, pelo método psicoprofilático, 216 gestantes solteiras, residentes no "Asilo Materno N.M.I." de Rovereto, Itália. Estudaram o comportamento dessas gestantes, durante o trabalho de parto, e classificaram 81\% como "ótimo" - estas gestantes apresentaram um comportamenta calmo durante todo o período do trabalho de parto, considerando a dor nerfeitamente suportável; $10 \%$ foram classificadas com o comportamento "bom", pois se queixaram pouro durante o período expulsivo e suportaram menos a dor. Apenas 2\% tiveram um comportamento medíocre, reclamando durante o trabalho de parto e suportando a dor dificilmente. Este grupo foi compararo ao de parturientes solteiras que não tiveram preparo para o parto durante a gestação, e os resultados obtidos foram os seguintes: $68 \%$ tiveram comportamento ótimo; $15 \%$, bom; $10 \%$, mediocre e $7 \%$, mau.

BRAGLIA (4) considerou como objetivos principais do seu trabalho, verificar se, em gestantes da classe média, 
FREDDI, W.E.S. - Influência dos exercícios respiratórios e do estado civil no comportamento da parturiente. Rev. Bras. Enf.; DF, $28: 7-19,1976$.

de várias categorias profissionais e de diferentes condiçōes civil e social, os resultados obtidos com a preparação psicofísica para o parto seriam análogos aos de outro grupo de gestantes de classe mais privilegiada e de condição sócio-econômica melhor. Contudo, na apresentação e discussão dos resultados, não faz menção ao estado civll das gestantes.

DEUTSCH (8) comenta que a gravidez llegítima pode reforçar o medo ao parto, condicionado na gestante; isso influenciará a sua reação durante o parto. Para a autora, a clência médica, atualmente, proporciona condições para dar-se à luz quase sem dor. Portanto, pode se acreditar que isto aumentará a tendência das mulheres a terem filhos, cumprindo uma importante tarefa social. Porém, "não fíca desvalorizado este processo tecnológico pelo fato de persistir, na nossa sociedade, o preconceito de que a maternidade deve ser ocultada como uma desgraça, a não ser que satisfaça a uma norma social definida?"

WOLFF NETO (36) comenta que as origens dos distúrbios emocionais da mulher durante o ciclo gravídico-puerperal são muito variáveis, podendo estar ligadas a idéias surgidas na infância e na adolescênca, a informaçōes erradas sobre a gravidez e o parto patológicos, ou às novas responsabilidades, à insegurança flnanceira, ao medo de perden o amor do marido, à llegitimidade da criança, etc.

AZZOLINE et al. (1) consideram que a maternidade constitul um trauma para a mulher considerada "em condiçōes normais". A reação da mãe solteira à maternidade é variável, pois dependerá do interesse demonstrado pelo pai da criança; freqüentemente este se desinteressa pelo filho, abandonando a mulher apenas venha a conhecer o seu estado gravídico. Esta, vendo-se abandonada, procura refugiar-se em algum lugar, fugindo de sua situação social, da curiosidade dos vizinhos e da crueldade dos familiares. Porém, durante o trabalho de parto, as suas preocupaçōes vão influir no seu comportamento.

O que se observa, tanto nas mais recentes publicaçōes, como na assistência à parturiente, é que o comportamento da mulher no parto é de suma importância, dadas as conseqüências que pode ter, seja no evolver do parto, seja no recém-nascido. Por outro lado, a nossa observação de um elevado número de parturientes coloca em evidência a resposta pessoal e diferente de mulher para mulher, a um fenômeno (o parto) que parecia ser igual, em linhas gerais. assim que, condição particular, como o estado civil da parturiente, parece determinar aspectos diversos no seu comportamento, durante o trabalho do parto. Parece-nos, também, que as parturientes que não tinham participado de curso de preparação para o parto eram beneficiadas pelos exercícios respiratórios recém-aprendidos e praticados. Apresentavam-se aparentemente menos tensas, comportando-se melhor e cooperando nas diferentes fases do parto.

De nossa parte, ensinando os exercicios respiratórios baseados nos métodos de Read e de Lamaze a um grupo de parturientes que não tiveram a oportunidade de freqüentar curso de preparação para o parto, durarte a gestação, propusemo-nos a:

- demonstrar a possibilidade de neutralizar-se a tensão emocional da parturiente e, conseqüentemente, de diminuir o seu desconforto, aumentar a sua cooperação e melhorar o seu comportamento durante o parto;

- verificar se o estado civil da parturiente influi no seu comportamento.

\section{POPULAÇAO}

Estudaram-se sessenta e duas (62) 
FREDDI, W.E.S. - Influência dos exercícios respiratórios e do estado civil no comportamento da parturiente. Rev. Bras Enf.; DF, $28: 7-19,1976$.

parturientes, todas primiparas, de gestação a termo, admitidas no Pronto Socorro Obstétrico do Amparo Maternal, que não participaram de curso de preparo para o parto. Estas parturientes foram divididas em dois grupos, e escolhidas por ordem de admissão, da seguinte forma: números impares grupo "experimental", que recebia ensino de exercícios respiratórios; números pares - grupo "controle", num total de 31 parturientes em cada grupo.

A idade das parturientes variou entre 15 e 27 anos, no grupo "experimental", e entre 16 e 26 anos, no grupo "controle".

Em relação ao grau de instrução, no grupo "experimental", 2 parturientes $(6,45 \%)$ eram analfabetas; $15(48,40 \%)$, alfabetizadas; $2(6,45 \%)$, com primário incompleto; $9(29,03 \%)$, com primário completo; $2(6,45 \%)$, com secundário incompleto, e $1(3,22 \%)$, com secundário completo. No grupo "controle", 4 $(12,90 \%)$ das parturientes eram analfabetas; $8(25,81 \%)$, alfabetizadas; 5 $(16,12 \%)$, romo o primárío incompleto; $11(35,50 \%)$, com primário completo; 2 $(6,45 \%)$, com secundário incompleto; e $1(3,22 \%)$, com secundário completo.

Quanto à ocupação, no grupo "experiment,al", 19 parturientes $(61,29 \%)$ se classificavam como de prendas domésticas; $9(29,03 \%)$, como empregadas domésticas, e $3(9,68 \%)$, como comerciárias: no grupo controle, $20(64,52 \%)$ se qualificaram como prendas domésticas, e $2(6,45 \%)$, como comerciárias.

No referente à raça, o grupo "experimental" era integrado por 16 parturientes brancas $(51,61 \%)$ e 15 negras $(48,39 \%)$; o grupo "controle", por 14 parturientes brancas $(45,17 \%), 1$ amarela $(3,22 \%)$ e 16 negras $(51,61 \%)$. Todas as parturientes eram brasileiras.

No tocante ao estado civil das parturientes, no grupo "experimental", 11 $(35,48 \%)$ eram solteiras, $14(45,17 \%)$ viviam maritalmente e $6(19,35 \%)$ eram casadas. No grupo controle, $17(54,85 \%)$ eram solteiras, $6(19,35 \%)$ viviam maritalmente e $8(25,80 \%)$ eram casadas.

As parturientes foram selecionadas por ordem de admissão e indistintamente distribuídas nos dois grupos, como relatado no início deste capítulo. Todas as parturientes selecionadas apresentavam gravidez com feto único. Foram observadas condições materno-fetais.

\section{CONDIÇOEES MATERNAS}

1.1. Colo uterino: esvaecido e cum dilatação de 3 a $5 \mathrm{~cm}$ nas parturientes dos dois grupos.

1.2. Contrações uterinas coordenadas e ritmicas: foram estudadas pela palpação abdominal, através da dinâmica uterina, sendo observados duração, intensidade, freqüência, intervalo e tônus; durante a admissão, os dados referentes às contracões foram os seguintes: em 10 minutos, de 2 a 3 contrações de fraca e média intensidade, com a duração de 30 segundos cada uma, com intervalos regulares e tônus normal nas parturientes dos dois grupos.

1.3. Canal ósseo: a avaliação da capacidade do canal ósseo foi feita pela pelvimetria e pela pelvigrafia interna digital, e procuramos seguir a seqüência recomendada por Moloy. Verificamos através desta avaliação, dados que mostram a normalidade da escavação pélvica, fator absolutamente indispensável do evolver do parto normal.

\section{CONDIÇÓES FETAIS}

2.1. Vitalidade fetal: fizemos o controle da vitalidade fetal pela ausência dos batimentos cardíacos do feto, logo após a admissão da parturiente; a freqüência variou entre 130 e 150 batimentos por minuto.

2.2. Apresentação: a pesquisa foi 
FREDDI, W.E.S. - Influência dos exercícios respiratórios e do estado civil no comp.rtamento da parturiente. Rev. Bras. Enf.; DF, 28:7-19, 1976.

realizada somente com apresentação cefálica fletida e insinuada.

2.3. Membranas ovulares - Algumas parturientes, ao serem admitidas, apresentavam rotura da bolsa amniótica; outras, não. No evoluir cio trabalho de parto, procediamos à rotura artificial, quando indicada.

\section{METODOS}

\section{TECNICA DOS EXERCICIOS RESPIRATÓRIOS}

Os exercícios respiratórios ensinados às parturientes do grupo experimental foram baseados nos Métodos de Read e de Lamaze. Adotamos, portanto, um método eclético, que melhor se adaptasse ao ensino às parturientes e à sua falta de preparo prévio. Descreveremos este método empregado na nossa pesquisa.

1.1. Antes de $5 \mathrm{~cm}$ de dilatação, a parturiente respira lenta e profundamente, ao mesmo tempo que relaxa, sob a forma de repouso - tranqüllidade.

1.2. Depois de $5 \mathrm{~cm}$ de dilatação, usamcs uma modificação do tipo "cachorrinho cansado" (panting of dog). Esta respiração, ensinada habitualmente à gestante, é rápida e superficial. E feita com a boca aberta, tanto na inspiração como na expiração, o que causa o ressecamento da mucosa bucal. Para evitar este desconforto, utilizamos a respiraçāo rápida e superficial, com a boca semifechada, como o assovio. São movimentos respiratórios superficiais e de pequena duração, cujo número é aumentado de acordo com a intensidade da contração uterina. Têm, como finaliace, evitar que o diafragma, no seu abaixamento inspiratório, excite o útero, comprimindo-o. No início da contração, a parturiente deve fazer uma respiração profunda, e, a seguir, a respiraçāo rápida e superficial. e aue termina com uma ou duas respiraçōes profundas.
1.3. Na fase de transição $(8$ a $10 \mathrm{~cm}$ de dilatação cervical), a parturiente respira rápida e superficialmente, alternando periodicamente este respirar com respirações normais. Tal respiração tem, como finalidade, evitar que a parturiente faça força antes que o colo esteja completamente dilatado.

1.4. No período expulsivo, a parturiente inspira e contém a respiração (bloqueio respiratório), levanta a cabeça, encostando o queixo ao peito e contraindo energicamente os músculos abdominais, relaxando o períneo. No desprendimento cefálico, a parturiente volta a respirar rápida e superficialmente. Este exercício foi ensinado para as parturientes dos grupos experimental e controle.

\section{ASSISTENCIA DE ENFERMAGEM A PARTURIENTE}

As parturientes dos dois grupos (" $\mathrm{k} z$ perimental" e "controle") foram por nós atendidas pessoalmente, desde a sua admissão até o 4..$^{\circ}$ período do parto.

Todas receberam cuidados de enfermagem de rotina em obstetrícia: explicávamos previamente o que iria ser feito e qual a finalidade de cada cuidado de enfermagem, a fim de conseguirmos a participação da parturiente. Seguimos o roteiro de identificação das necessidades da parturiente, como está relatado no Guia de Enfermagem Obstétrica, descrito por FREDDI et al.. (12) procurando dispensar a cada uma, indistintamente, assistência de enfermagem obstétrica, de acordo com as necessidades identificadas no evoluir do trabalho de parto. Enfase fol dada ao apoio emocional, durante os diferentes estágios do parto, visando principalmente a ajudar a mãe a sentir-se satisfeita em participar ativa e eficientemente no nascimento de seu filho.

Foram administradas drogas ocitócicas (Byntocinon) e antiespasmódicas 
FREDDI, W.E.S. - Influência dos exercicios respiratórios e do estado civil no comp.rtamento da parturiente. Rev. Bras. Enf.; DF, 28:7-19, 1976.

(Buscopan, Diempax ou Dolantina), a critério do médico obstetra responsável pelo plantão, nas parturientes dos dois grupos.

Os partos foram normais e em todas as parturientes recorremos à episiotomia médio-lateral direita, sob anestesia local.

2.1. Educação das parturientes.

Transmitimos conhecimentos elementares sobre os órgãos da reprodução, o desenvolvimento do feto e o trabalho de parto, às parturientes dos dois grupos, com a finalidade de diminuir a ansiedade em relação ao desconhecido. Para melhor compreensão das parturientes, utilizamos desenhos do "Birth Atlas" publicado pela "Maternity Center Association" (s.d.).

2.2. Relaxamento muscular.

Procuramos ensinar o relaxamento muscular a partir dos $4 \mathrm{~cm}$ de dilatatacão, proporcionando posirão confortável à parturiente (grupo "experimental" e grupo "controle") e através da ordem verbal "fique calma e solte completamente seu corpo sobre a cama". No periodo expulsivo, o relaxamento era praticado nos intervalos das contraçōes.

\section{COMPORTAMENTO DAS PARTURIENTES.}

Avaliamos o comportamento de 52 parturientes, medicadas ou não, durante o trabalho de parto e o parto.

Para tanto, usamos um critério que melhor se adaptasse às condiçōes em aue a pesquisa estava sendo realizada. Este critério, que descreveremos a seguir, fol adaptado do utilizado por KARTCHNER (18) e apresenta a pretendida similitude ao trabalho que fizemos.

3.1. Muito bom.

3.1.1. A parturiente, durante o trabalho de parto, com ou sem medicamento, mantém-se controlada, embora possa demonstrar alguma apreensão sobre a evolução do parto.

3.1.2. A parturiente não grita, nem se agarra à cama, nem apresenta contração de mãos e contorçōes.

3.1.3 capaz de repousar tranqüilamente durante e entre as contraçōes. No periodo de transição apresenta rubor e sudorese facial, tensão muscular durante as contraçōes. e pede informaçōes sobre o término do parto.

3.1.4. Coopera durarte as contraçōes do período expulsivo, mantendo seu relaxamento nos intervalos das contraçōes.

3.1.5. No quarto período, mostra-se animada, satisfeita consigo mesma e com a própria experiência do parto. Não apresenta reaçōes desagradáveis (como o sentimento de que perdeu alguma coisa), depressão, ansiedade e rejeição ao bebê.

\subsection{Bom.}

3.2.1. A parturiente, durante o trabalho de parto, com ou sem medicação descontrola-se em grau minimo e ocasionalmente.

3.2.2 Grita, de vez em quando, nas contraçōes, e apresenta um pouco ie tensão. Não se agarra à cama, nem apresenta contraçōes e contorçōes de mãos.

3.2.3. Repousa a maior parte do tempo entre as contraçōes. Pode queixar-se de desconforto, no período de transição.

3.2.4. Coopera, durante as contraçōes do periodo expulsivo, mantendo o relaxamento nos intervalos das contraçōes.

3.2.5. Embora tenha algumas lembranças de desconforto, fica animada e satisfeita consigo mesma, e não pensa no parto como uma experiência desagradável.

3.3. Regular.

3.3.1. A parturiente, com ou sem 
FREDDI, W.E.S. - Influência dos exercícios respiratórios e do estado civil no comportamento da parturiente. Rev. Bras Enf.; DF, 28: 7-19, 1976.

medicação, descontrola-se durante $50 \%$ do tempo do trabalho de parto.

3.3.2. Grita, geme, apresenta rigldez muscular, contração das mãos e contorçōes, em $50 \%$ do tempo do trabalho de parto.

3.3.3. Repousa entre as contraçōes, durante $50 \%$ do tempo do trabalho de parto, descontrolando-se no período de transição.

3.3.4. No segundo estágio, e ao aproximar-se o fim do parto, descontrola-se completamente.

3.3.5. No quarto período do parto, sente-se animada e satisfeita, mas também acha que o parto é situação muito dolorosa e desagradável. Freqüentemente, manifesta a disposição de não repetir a experiência.

3.4. Sofrível.

3.4.1. A parturiente, com ou sem medicação, descontrola-se completamente, durante $o$ trabalho de parto $\mathrm{e}$ o parto.

3.4.2. Grita, durante as contraçōes, desde 0 início do trabalho de parto. Apresenta rigidez muscular, tensão. contração de mãos, contorçōes e apreensão de objetos próximos. Grita pela mãe, marido ou outras pessoas, e por ajuda.

3.4.3. incapaz de repousar ou controlar o comportamento durante todo o parto.

3.4.4. Durante o período expulsivo, é incapaz de participar voluntariamente rejeitando, muitas vezes, o apoio oferecido pelos assistentes.

3.4.5. No quarto período do parto, lembra-se da experiência como algo horrível, para nunca ser repetido. Apresenta reaçōes desagradáveis, depressão e ansiedade. Ocasionalmente, neste gripo, a parturiente pode sentir e expressar satisfação neste período.

\section{RESULTADOS}

De acordo com os critérios adotados para o estudo do comportamento das parturientes, constatamos que a execução dos exercícios respiratórios, durantes o trabalho de parto, auxiliou às parturientes do grupo experimental a manterem melhor comportamento durante a evolução do mesmo. Agrupandn os resultados "muito bom" e "bom", para termos cifras expressivas, constatamos que foram assim classificadas 22 parturientes $(71,0 \%)$ do grupo "experimental". No grupo "controle", esta classificação foi obtida por 15 parturientes $(48,38 \%)$. Outro fato que gostaríamos de salientar é que, na classificação "sofrível", do grupo "experimental", houva uma única parturiente, enquanto que no grupo "controle", cuja assistência de enfermagem foi idêntica à do grupo "experimental", com exceção da ausência dos exercícios respiratórios, classificaram-se 7 parturientes. Os resultados obtidos podem ser observados no quadro 1.

QUADRO 1

Classificação do comportamento das parturientes, nos grupos "experimental" e "controle".

\begin{tabular}{|c|c|c|c|c|}
\hline \multirow[b]{2}{*}{ Comportamento } & \multicolumn{2}{|c|}{ Grupo "experimental" } & \multicolumn{2}{|c|}{ Grupo "controle" } \\
\hline & $\begin{array}{l}\text { Número de } \\
\text { Casos }\end{array}$ & $\%$ & $\begin{array}{l}\text { Número de } \\
\text { Casos }\end{array}$ & $\%$ \\
\hline Muito Bom & 12 & 38,71 & 7 & 22,58 \\
\hline Bom & 10 & 32,27 & 8 & 25,80 \\
\hline Regular & 8 & 25,80 & $\boldsymbol{\theta}$ & 29,04 \\
\hline Sofrível & 1 & 3,22 & 7 & 22,58 \\
\hline TOTAL & 31 & 100,00 & 31 & 100,00 \\
\hline
\end{tabular}


FREDDI, W.E.S. - Influência dos exercícios respiratórios e do estado civil no comportamento da parturiente. Rev. Bras. En?.; DF, $28: 7-19,1976$.

No grupo "experimental", houve uma incidência de 11 parturientes $(35,48 \%)$ solteiras, das quais $8(\mathbf{7 2 , 7 2 \% )}$ tiveram o seu comportamento classificado como "muito bom" e "bom" e 3 (27,28\%) classificaram-se como "regular" e "sofrível". No grupo "controle", 17 parturientes $(54,85 \%)$ eram solteiras e destas, $7(41,17 \%)$ foram classificadas como tendo comportamento "muito bom" e "bom" e 10 (58,83\%) como "regular" e "sofrível".

Agrupando as parturientes casadas e as que vivem maritalmente, tivemos um total de $20(64,52 \%)$ no grupo "experimental", das quais 14 (70\%) classificaram-se com o comportamento "muito bom" e "bom" e 6 (30\%) tiveram comportamento "regular" e "sofrível". No grupo "controle", o agrupamento destas parturientes deu um total de 15 $(48,38 \%)$, sendo que 8 parturientes $(53,33)$ tiveram comportamento classificado como "muito bom" e "bom e 7 $(46,66 \%)$ classificaram-se com o comportamento "regular e "sofrível". Os resultados obtidos podem ser observados no quadro II.

\section{QUADRO 2}

Classificação do comportamento das parturientes nos grupos "experimental" e "controle", relacionado ao estado civil.

\begin{tabular}{|c|c|c|c|c|c|c|}
\hline \multirow{3}{*}{$\begin{array}{l}\text { Comporta- } \\
\text { mento }\end{array}$} & \multirow{2}{*}{$\frac{\text { Grupo }}{\text { Casadas }}$} & \multicolumn{2}{|c|}{ Experimental" } & \multirow{2}{*}{$\frac{\text { Grup }}{\text { Casadas }}$} & \multicolumn{2}{|c|}{ "Controle" } \\
\hline & & Solteiras & $\begin{array}{c}\text { Vivem } \\
\text { Maritalmente }\end{array}$ & & Solteiras & $\begin{array}{c}\text { Vivem } \\
\text { Maritalmente }\end{array}$ \\
\hline & $\begin{array}{c}\text { N. }{ }^{\circ} \text { de } \\
\operatorname{casos}\end{array}$ & $\begin{array}{l}\text { N. }{ }^{\circ} \text { de } \\
\operatorname{casos}\end{array}$ & $\begin{array}{c}\text { N. }{ }^{0} \mathrm{de} \\
\operatorname{casos}\end{array}$ & $\begin{array}{c}\text { N. }{ }^{0} \mathrm{de} \\
\operatorname{casos}\end{array}$ & $\underset{\text { casos }}{\text { N. de }}$ & $\begin{array}{l}\mathrm{N}^{0} \mathrm{de} \\
\operatorname{casos}\end{array}$ \\
\hline Muito Bom & $\begin{array}{c}2 \\
(6,45)\end{array}$ & $\begin{array}{c}3 \\
(9,67)\end{array}$ & $\begin{array}{c}7 \\
(22,58)\end{array}$ & $\begin{array}{c}3 \\
(9,67)\end{array}$ & $\begin{array}{c}2 \\
(6,45)\end{array}$ & $\begin{array}{c}2 \\
(6,45)\end{array}$ \\
\hline Bom & $\begin{array}{r}2 \\
(6,45)\end{array}$ & $\begin{array}{c}5 \\
(16,12)\end{array}$ & $\begin{array}{c}.3 \\
(9,67)\end{array}$ & $\begin{array}{c}2 \\
(6,45)\end{array}$ & $\begin{array}{c}5 \\
(16,12)\end{array}$ & $\begin{array}{c}1 \\
(3,22)\end{array}$ \\
\hline Regular & $\begin{array}{r}2 \\
(6,45)\end{array}$ & $\begin{array}{c}2 \\
(6,45)\end{array}$ & $\begin{array}{c}4 \\
(12,90)\end{array}$ & $\begin{array}{c}1 \\
(3,22)\end{array}$ & $\begin{array}{c}7 \\
(22,58)\end{array}$ & $\begin{array}{c}1 \\
(3,22)\end{array}$ \\
\hline Solrivel & $\begin{array}{r}0 \\
-\end{array}$ & $\begin{array}{c}1 \\
(3,22)\end{array}$ & $\begin{array}{c}0 \\
-\end{array}$ & $\begin{array}{c}2 \\
(6,45)\end{array}$ & $\begin{array}{c}3 \\
(9,67)\end{array}$ & $\begin{array}{c}2 \\
(6,45)\end{array}$ \\
\hline TOTAL & $\begin{array}{r}6 \\
(19,35)\end{array}$ & $\begin{array}{c}11 \\
(35,48)\end{array}$ & $\begin{array}{c}14 \\
(45,16)\end{array}$ & $\begin{array}{c}8 \\
(25,80)\end{array}$ & $\begin{array}{c}17 \\
(51,61)\end{array}$ & $\begin{array}{c}6 \\
(19,35)\end{array}$ \\
\hline
\end{tabular}

* Os números entre parênteses correspondem ds percentagens.

\section{DISCUSSĀO}

A maioria dos autores adeptos dos diversos métodos de preparação para 0 parto, dão ênfase aos resultados úteis ao parto, resultados estes obtidos na diminuição ou abolição da dor, na parturiente que adquiriu novos reflexos condicionados e às suas reações frente a esta nova situação. óbvio que, abolindo ou 
FRHDDI, W.E.S. - Inlluẻnria cina exercícios respiratórios e do estado civil no compjrtamento da parturiente. Rer. Bras Enf.; DF, 28 : 7-19, 1979.

atenuando a dor e a sua repercussão nociva sobre o organismo materno, outros benefícios advêm para o binômio mãe - feto. As parturientes que praticaram os exercícios respiratórios (grupo "experimental") apresentaram um comportamento mais adequado que os do grupo "controle".

Analisando-se os resultados descritos e relacionados no quadro $I$, verificamos que 22 parturientes do grupo experimental ( $71 \%$ ) estão classificados com o comportamento "muito bom", e "bom" 9 (29\%), "regular e "sofrível". No grupo controle, um maior número de parturientes foi incluído na classificação "regular' e "sofrível", totalizando 16 $(51,62 \%)$. Com o comportamento "muito bom" e "bom", foram classificadas 15 parturientes, $(\mathbf{4 8 , 3 8 \% )}$ ) deste grupo. Considerando estes fatos, concluímos que o melhor comportamento das parturientes do grupo experimental, durante o trabalho de parto e o parto, fol conseguido através da prática dos exercícios respiratórios.

SCHWARCZ (31), em um estudo de primíparas sem preparação prévia e condicionadas durante 0 trabalho de parto, apresentou $73,1 \%$ de resultados "bons", sendo que, destes, $19,8 \%$ foram "muitos bons". Os dois estudos não são comparáveis, pois, no de Schwarcz, as sensacōes dolorosas das parturientes são usadas como importante critério de avaliação, enquanto que, em nossa pesquisa, não tiveram o mesmo valor. Mas é interessante notar que, nos dois estudos, houve uma proximidade de resultados, levando-se em consideração que Schwarcz aerupou os resultados "Bons" e "Muito Bons", para obter, segundo assinalou, cifras mais expressivas. Resultados menos significativos, quanto ao controle da dor, foram relatados por TONNELIER e MOGGIA (34), que consideraram, na primeira metade da dilatação, $41,18 \%$ de êxito, com uma queda para $37,55 \%$, na segunda metade deste período. Já no expulsivo, os resultados foram mais expressivos, conseguindo-se o indice de $\mathbf{8 2 , 2 8 \%}$. Os autores consideram em separado o fator emocional, anotando, no período de dilatação, $81,75 \%$ como resultados bons e, no expulsivo, $82,28 \%$. Há porém, um fato, a nosso ver, que deve ter influído nos resultados obtidos por Tonnellier e Moggia. o preparo da equipe do pessoal de enfermagem e de todas as pessoas, que, incidentalmente, entraram em contato com a parturiente. O Instituto e Maternidade "Ramon Sardá": onde Tonnellier e Moggia realizaram a referida pesquísa, conta com enfermeiras obstétricas especializadas no preparo psicoprofilático para o parto, cuja única função é a de aplicar a prepara. ção psicoprofilática de emergência, não dando assistência obstétrica propriamente dita.

Neste pormenor, tivemos algumas dificuldades. No nosso estudo, as parturientes do grupo experimental levaram algum tempo para executar adequadamente os exercícios respiratórios; algumas pediam insistentemente que executássemos com elas estes exercícios e outras necessitavam de maior estímulo para aplicá-los. Isto significava uma solicitação contínua de nossa atenção, o que era impraticável, de vez que também éramos responsáveis pelos cuidados de enfermagem e de otstetrícia. $O$ mesmo problema ocorria, no tocante ao reconhecimento do início da contração. As nossas parturientes, que não foram treinadas na gestação, tinham dificuldades em reconhecer o início da contração, retardando o começo do exercício respiratório, em prejuízo do que recomendam os autores. Este é um fato que exige a presença constante do profissional ao lado da parturiente não preparada, para avisá-la quando deve começar o exercícto. Na realidade, os autores Blank (2), Yahia et al. (37), 
FREDDI, W.E.S. - Influência dos exercícios respiratórios e do estado civil no comportamento da parturiente. Rev. Bras Enf:; DF, 28:7-19, 1976.

Novas Angel (25) e McClaren (23) aconselham que as parturientes preparadas para o parto recebam uma atenção constante, sendo estimuladas e corrigidas quanto ao tipo de exercício respiratório, sempre que isto for necessário. Sentindo o apoio do profissional que as assiste, elas reforçam, cada vez mais, o reflexo condicionado "respiração - contração".

Embora as parturientes classificadas com comportamento "muito bom' e "bom" tivessem sensaçōes dolorosas atenuadas, este critério não pesou na nossa avaliação do comportamento. Consideramos que não houve, durante a gestação, a substituição do reflexo condicionado "contração-dor' pelo reflexo "contração-respiração". Além disto, as parturientes eram admitidas em franco trabalho de parto, presas de ansiedade por terem, em sua maioria, transitado por outras maternidades à procura de atendimento. Estas condições são negativas dentro do processo de abolíção da dor. Por outro lado, fortalecem o condicionamento "contração-dor", adquirido no contato com parentes e amigos, cujos preconceitos e crendices se integraram na sua conceituação antecipada da experiência do parto. Nestas condições, procuramos reconhecer a causa da sensação dolorosa, objetivando minorá-la na medida do possível. Nas circunstâncias em que o estudo fol realizado ficamos satisfeitas com o número significante de parturientes que, com a prática dos exercícios respiratírios, suport?.ram facilmente o trabalho de parto, apresentando um comportamento que variou entre "muito bom" e "bom".

Em vista dos resultados apresentados, procuramos saber também se o estado civil teve influência nas respostas obtidas.

Analisando-se os resultados apresentados no quadro II, constatamos que 11 parturientes $(35,48 \%)$ eram solteiras e, destas, $8(\mathbf{7 2 , 7 2 \% )}$ estão classificadas com o comportamento "muito bom" e "bom". Apenas $3(27,28 \%)$ tiveram o seu comportamento classificado como "regular' e "sofrivel". Resultado semelhante pode ser observado entre as parturientes casadas e as que vivem maritalmente; das $20(64,52 \%)$ assim agrupadas, 14 (70\%) classificaram-se com o comportamento "muito bom" e "bom". O agrupamento das parturientes casadas e das que vivem maritalmente parece-nos justificável, pois ambas têm o apoio do companheiro, tido como um fator importante no ajustamento da mulher às modificações do ciclo grávido-puerperal. AZZOLINI et al (1) destacam a importância do pal da criança, nas reações emocionais tanto da gestante como da parturiente e da puérpera.

Embora a condição de solteira, geralmente, possa influir negativamente nas reaçōes da parturiente, observamos, no grupo experimental, que tanto as solteiras como as casadas e as que vivem maritalmente foram beneficiadas concentrando-se na execução dos exercícios respiratórios, conseguindo controlar-se, relaxar e cooperar durante o trabalho de parto.

Em nossas parturientes do grupo "controle", observamos que as casadas e as que vivem maritalmente cooperaram mais e apresentaram melhor comportamento que o das solteiras do mesmo grupo. Notamos, porém, que a diferença existente entre as solteiras e casadas e que vivem em concubinato, classificadas com o comportamento "muito bom" $\mathrm{e}$ "bom", é minima.

VISENTINI et al (35) em parturientes solteiras preparadas para o parto, obteve, como comportamento "ótimo", 81\%. Embora não sendo comparável ao nosso estudo, parece-nos interessante a proximidade dos resultados obtidos na avaliação do comportamento das parturientes solteiras do grupo experimen- 
FREDDI, W.E.S. - Influência dos exercícios respiratórios e do estado civil no comportamento da parturiente. Rev. Bras En?.; DF, $28: 7-19,1976$.

tal. Em nossa pesquisa, assinalamos $\mathbf{7 2 , 7 2 \%}$, provavelmente pelo fato de termos ensinado os exercícios respiratórios durante o trabalho de parto. 0 mesmo autor, em parturientes solteiras não preparadas, obteve $68 \%$ com o comportamento "ótimo"; em nossa pesquisa, $43,75 \%$ das parturientes solteiras, do grupo controle, obtiveram classificação semelhante.

Diante dos fatos apresentados, concluímos que:

1. As parturientes que praticaram os exercícios respiratórios, durante o trabalho de parto, apresentaram melhor comportamento e cooperaram mais com a equipe profissional.
2. No grupo "experimental", tanto as parturientes solteiras como as casadas e as que vivem maritalmente, e que praticaram os exercícios respiratórios, durante o trabalho de parto, apresentaram comportamento "muito bom" e "bom".

3. No grupo "controle", as parturientes casadas e as que vivem maritalmente apresentaram melhor comportamento e cooperaram mais com a equipe profissional, em relação às parturientes solteiras.

4. Os exercícios respiratórios não excluem a necessidade que a parturiente tem de receber apoio emocional das pessoas que a assistem.

\section{REFGRENCIAS BIBLTOGRAFICAS}

1. AZZOLINI, E. et al. The social problem of pregnancy in the girl of marriageable age. Professioni Infermierestiche, 23 (2) : 65-68, marabr., 1970.

2. BLANK, B. Nuestra experiencia com el metodo de Read. Rev. Med. Córdoba, 44: 23-43, 1956.

3. BOCCI, A. et al. Il parto naturale con il metodo psicofio-terapico. Fondamente teorici e risieltati clinici Min. Gin., 11: 11, 1956.

4. BRAGLIA, C. La preparazione materterna nel parto: considerazioni e contributo personale su un biennio di applicazione del metodo presso in Centro della Scuola di Obstetricia di Montova. Quad Ch. Obstec. Ginec., 15: 692-726, oct. 1960

5. CERRUTI, F. Nossa experiência com o assim chamado parto sem dor. Rev. de Ginec. e d'Obstetricia, 99: 645-766, 1956.

6.

- A preparação psicossomática para o parto (in REZENDE, J. et al. - Obstetricia. Rio de Janeiro, Guanabara-Koogan, 1962. (v. 1, p. 374-386).

7. CHFRTOK, L. Les méthodes psychosomatiques d'accouchement sans doleur. 2 éme ed. Paris, L'expansion Scientifique, 1958.

8. DEUTCH, H. La psicologla de la mujer. Buenos Aires, Losada, 1960.
9. DONATO, V.M. La psicoprofilaxis en una maternidad municipal. Obstetricia y Ginecologia LatinoAmericanas, 21: 573-578, 1963.

10. DONEHC, H.C. \& GLICK, S.J. The nurse and the unwed mother. Nursing outlook, 2: 249-51, may, 1954.

11. FERNANDEZ, B.M.A. As aulas teóricas. Rev. Colombiana de Obst. J Ginec., 18: 277-280, 1567.

12. FRADDI, W.E. \& MARTINS, H.A.L. Guia de estudo de enfermagem obstétrica. Rev. Esc. Enf. USP, 6 (1-2) : 129-256 mar.-set., 1972.

13. GAVEnSKY, R.V. Psicoprofilaxis obstetrica. Buenos Aires, El Ateneo, 1971.

14. GOODRICH, F.W. Preparação para o parto. Rio de Janeiro, Block, 1971.

15. GUASTALA, L. La preparazone estemporanea al parto naturale. Minerva Ginecológica, 11: 1020-1, 1959.

16. HEARDMAN, H. A way to natural child birth. Baltimore, Williams \& Willkins, 1950.

17. HIRsh, L. Sensible childbirth. General Practiotiner, 7: 61-64, 1953.

18. RARTCFNER F.D. A study of the emotional reactions durin labor. Amer. J. Obst. \& Gyn., 60: 19-28, 1850. 
FREDDI. W.E.S. - Influência dos exerć́cios respiratórios e do estado civil no comportamento da parturiente. Rev. Bras. Enf.; DF, 28 : 7-19, 1976.

19. LAMAZE, F. \& VELLAY, P. L'accouchement sans douleur por la méthode psychophysique Goz. Med., 59 (23) : 1.445, 1952.

20. LAMAZE, F. et al. Parto sem dor. S.L.P., Ed. Vitória, 1956.

21. — El parto sin dolor por el metodo psicoprofilactico. Boletin de la Sociedade de Obstetricia y Ginecoloia de Buenos Aires. 2462621956.

22. MATERNITY CENTER ASSOCIATION Birth Atlas. New York, s.d.

23. MCCLAREN, J.B. Maternal respiration in labour. Midwives Chroninicle, 83: 112-4, 1970.

24. NICOLAIEV, A. El parto sin dolor. Buenos Aires, Cartago, 1957.

25. NOVAS ANGEL, $H$. La atencion del parto por el metodo psicoprofilactico. Rev. Colombiana de Obstetricia y Ginecologia, 18: 249-254. 1967.

26. PIERFEDERICI, P. Valutazione degli effetti della preparazione psicofisica al parto: studio condotto con metodo statistico. Rev. Ital. Ginec., 45: 27-57, 1961.

27). READ, G.D. Natural childbirth. London, Heinemann, 1933.

28. Childbirth without fear. New York, Harper and Brothers, 1944.

29. SALA, S.I. Pasado y futuro de la psico-profilaxis obstetrica. Obstetricia $\boldsymbol{y}$ Ginecologia Latino-Americanas: 694-701, 1963.
30. SBRIGLIO, V.S. \& TERZI, I. La fono-stimolazione della respirazione stereoritmata nella preparazione psicosomatica al parto. Minerva Ginecológica, 18: 1096-1072, 1966.

31. SCHWARCZ, R. Resultados de nuestra experiencia con el método psicoprofilactico. Boletim de la Sociedad de Obstetricia y Ginecologia de Buenos Aires, 35: 110-115, 1956.

32. SCHWARTZ, M. Praktische erfahrungen mit der körperlich - seelischen vorbereitung auf die geburt. Deustsches Medizinisches Journal, 14: 286-9, 1963.

33. THOMS, H. Training for childbirth. New York, McGraw-Hill, 1950.

34. TONNELLIER, E. G. \& BOGGIA, A.V. Acondicionamento de emergência en psico-profilaxis. Obstetricia y Ginecologia Latino-Americanas: 206-208, 1963.

35. VISENTINI, F. et al. Il parto psicoprofilattico nelle madri nubili. Rev. Obst. Gin. Prat., 41: 406411, 1959.

36. WOLFF NETO, A. Aspectos psicológicos do ciclo grávido-puerperal (in REZENDE, J. et al. Obstetrícia. Rio de Janeiro, Guanabara-Koogan, 1962, v. 1, p. 270-277).

37. YAHIA, C. \& ULIN, P. R. Preliminary experience with e psychophysical program of preparation for childbirth. Amer. J. Obst. \& Gyn., 93: 942-9, 1965. 